\title{
¿Males pasajeros? E1 Partido Socialista frente a las consecuencias de la Ley Sáenz Peña
}

\author{
Ricardo Martinez Mazzola \\ CONICET-UNSAM-UBA \\ ricardomm17@yahoo.com
}

\begin{abstract}
El presidente Sáenz Peña, como el presidente Figueroa, como el presidente Quintana, en su hora solemne ha hablado de la libertad electoral y de la constitución de partidos orgánicos hasta hoy inexistentes. Yél, como todos los otros, ha expresado el pensamiento pueril de la providencia oficial: los partidos van a nacer cuando el presidente de la república se decida a crearlos; la vida politica sana y fecunda va a brotar milagrosamente cuando el gran mago de la Casa Rosada agite su vara llamándola a luz.
\end{abstract}

(La Vanguardia, 18 de febrero de 1911)

Sin haber esperado jamás milagros de la Ley Sáenz Peña, estamos, más que nunca, convencidos de su honda y duradera trascendencia politica, ella ha dado al pueblo el instrumento primario de la democracia, sin cuya posesión es imposible todo progreso politico. Con su uso el pueblo se capacitará, cada vez más, a manejar mejor el instrumento.

(La Vanguardia, 7 de agosto de 1918)

A fines de 1910 Roque Sáenz Peña asumió la Presidencia de la Nación Argentina sosteniendo como principal bandera la necesidad de llevar adelante una profunda reforma electoral. Como muestra la primera cita, las propuestas de Saénz Peña fueron recibidas con escepticismo por parte de un Partido Socialista (PS) que, aunque hacía tiempo bregaba por una reforma tal, desconfiaba de la figura del viejo dirigente modernista y, más en general, de las soluciones que surgían de la cumbre del

(Archivos, año III, nº 6, pp. 53-72) 
Estado para transformar la sociedad. Contra las expectativas socialistas, la iniciativa de Sáenz Peña alcanzaría éxito y, como reconoce la segunda cita, afectaría profundamente la vida politica argentina y también, como pronto comenzarian a plantear con preocupación algunos dirigentes socialistas, la vida interna del propio PS.

Desde hace décadas numerosos historiadores y científicos sociales han echado luz sobre el intrincado proceso que derivó en la "Ley Sáenz Peña", ${ }^{1}$ destacando el profundo impacto de la modificación del mecanismo electoral sobre el sistema político argentino. En cambio, la posición que frente a la nueva legislación sostuvieron los socialistas solo ha sido abordada por Scherlis (2005) en dos trabajos que, concentrados en el modo en que la reforma modificó el lugar del PS en el sistema político, dejan en un segundo plano consecuencias de esas modificaciones sobre la estructura y los alineamientos internos del PS.

En este artículo nos proponemos dar cuenta del impacto de la Ley Sáenz Peña, que ampliaba y complejizaba el universo de participación política, sobre la organización y la vida interna del PS. El recorrido propuesto tiene tres etapas: en primer lugar, y luego de pasar revista al modo en que los socialistas se colocaron frente a propuestas de reforma, deteniéndonos brevemente en los cambios que produjo la elección de Alfredo Palacios en 1904, revisaremos las posiciones del PS en los debates que condujeron a la sanción de la Ley Sáenz Peña. En segundo lugar abordaremos cómo fueron recibidos los, sorprendentemente positivos, resultados socialistas en las elecciones porteñas que siguieron a la sanción de la reforma, lo que implica abordar las elecciones de 1912 y los comicios que en 1913 y 1914 dieron el triunfo al PS. En tercer lugar, y centrándonos en el decisivo XII Congreso del PS, realizado en mayo de 1914, señalaremos el modo en que los propios socialistas percibieron y afrontaron los desafios nacidos del crecimiento experimentado por el partido a partir de la sanción de la nueva legislación electoral. Concluiremos planteando algunos argumentos más generales respecto a los desafios a los que los socialistas se vieron sometidos a partir de la vigencia de la Ley Sáenz Peña.

\section{El PS ante las propuestas de reforma electoral}

Para el sentido común la Ley Sáenz Peña estableció el sufragio universal masculino en la República Argentina. No es así: el sufragio universal

1. Se conoce como "Ley Sáenz Peña" a la ley $\mathrm{n}^{\circ}$ 8.871, que estableció el sufragio universal masculino obligatorio y el sistema de lista incompleta. Debe aclararse que también suele incluirse bajo el nombre de "Ley Sáenz Peña" a la ley 8.130 que definía la creación de un padrón electoral permanente en base al enrolamiento militar. 
masculino regía desde el siglo XIX y en la Provincia de Buenos Aires había sido establecido en 1821 bajo el gobierno de Martín Rodríguez. Sin embargo, a comienzos del siglo XX la participación electoral era limitada y, quizás más importante, controlada. El voto no era secreto, los padrones eran elaborados por autoridades politicas parciales, las juntas escrutadoras solian quedar en manos de las facciones. Los comicios oscilaban entre el fraude mecánico y las batallas entre las máquinas electorales de las distintas facciones. Por otra parte, la lógica guerrera era alimentada por el sistema de "lista completa" que hacía que quien lograra imponerse en la elección obtuviera todos los cargos en disputa.

Desde fines del siglo XIX distintos sectores politicos opositores demandaron medidas que garantizaran el "voto libre" y posibilitaran la representación de una sociedad cada vez más compleja. Desde sus primeros días los socialistas, aunque divididos respecto a la centralidad de la lucha politica (Poy, 2014), se colocaron entre quienes reclamaban una reforma electoral, siendo particularmente insistentes en la demanda de mecanismos que permitieran la representación de las minorías. En rigor, los planteos socialistas en esa dirección anteceden a la fundación formal del PS: ya en la reunión de abril de 1894, en la que los clubes Les Egaux, Fascio dei lavoratori y Agrupación Socialista decidieron la formación de un partido socialista, se aprobó un Programa Mínimo, que demandaba la representación de las minorias (Oddone, 1983: 25).

Los debates en torno a la cuestión electoral tomaron un tono más concreto a mediados de 1902, momento en que el Ministro del Interior del gobierno de Julio A. Roca, Joaquín V. González, presentó su proyecto de reforma electoral. Mientras algunos socialistas lo juzgaban como "bueno y hasta excelente" porque consagraba muchas de las aspiraciones en materia de reforma electoral, poniendo al partido en condiciones de aumentar su representación, otros rechazaban el sistema uninominal, ${ }^{2}$ argumentando que no solo no se acercaba a la representación proporcional sino que impedia su posterior implantación. Fue en el clima político y social tenso que seguia a la gran huelga portuaria de noviembre de 1902 y a la posterior sanción de la Ley de Residencia que, bajo estado de sitio, el Congreso Nacional aprobó la reforma electoral. No sorprende entonces que la misma fuera recibida friamente por la socialistas, quienes denunciaron el modo en que el gobierno roquista diseñaba las circunscripciones, constituía las "juntas de distrito" y fraguaba los padrones electorales. Poco hacía prever que bajo la nueva legislación el PS obtendría su primer representante parlamentario. Sin embargo, en marzo de 1904 Alfredo Palacios fue electo diputado por la $4^{\mathrm{a}}$ sección

2. Por este sistema cada distrito se dividía en tantas secciones como cargos a llenar y en cada una de ellas se elegía a un candidato por mayoría simple. 
electoral, la Boca. ${ }^{3}$ El siguiente número de La Vanguardia (LV), titula con entusiasmo y espíritu internacionalista: "Victoria Socialista. Las elecciones del 13 de Marzo de 1904, en Buenos Aires han dado a la clase obrera el primer diputado socialista en la América del Sud. ¡Viva el Partido Socialista Internacional!" (LV, 19 de marzo de 1904).

A partir de la elección de Palacios se fortalecieron las posiciones de quienes tendian a poner en un lugar central la participación electoral y la acción parlamentaria, al tiempo que aumentaba la exposición pública del PS pero, sobre todo, del mismo Palacios. ${ }^{4}$ Se colocaban así los fundamentos que marcarán la institucionalización del partido en los años que siguen (1905-1910): la centralización del poder organizativo y el predominio de la agitación electoral y la acción parlamentaria. Estos rasgos se pusieron ya de manifiesto en el VII Congreso del PS realizado en 1906, en el que los seguidores de Justo impusieron su posición en la vida partidaria, "invitando" a los simpatizantes de las ideas sindicalistas, entre los que se contaba la conducción de la Unión General de los Trabajadores, a abandonar el partido. Sería también en esos años que comenzaria a plantearse un conflicto tradicional en los partidos socialistas, el que enfrentaba al "núcleo interno" con figuras parlamentarias como la de Palacios. La dinámica partidaria que reforzaba a la vez la centralización y la orientación parlamentaria del partido daría lugar a frecuentes conflictos y duras polémicas -sobre la "cuestión nacional", la "cuestión religiosa", sobre las alianzas políticas- que anticipaban la ruptura abierta que seguiria a los éxitos electorales que el PS experimentaría a partir de la sanción de la Ley Sáenz Peña

\section{Hacia la Ley Sáenz Peña}

El PS que, como vimos, no había apoyado la implantación del sistema de circunscripciones uninominales para las elecciones de diputados, sí lamentó cuando a mediados de 1905, el gobierno de Manuel Quintana

3. Juan Carlos Torre (2012: 46-47) sostiene que el triunfo de Palacios no se explica sólo por el apoyo de los socialistas o siquiera por el de los liberales y anticlericales italianos de la Boca, que habian hecho explícita la adhesión a su candidatura. Palacios, subraya, obtuvo también la adhesión de los mitristas quienes, sabiendo merced al carácter público del voto que su candidato no tenía posibilidades, concentraron en él sus votos para derrotar al candidato del PAN Marco Avellaneda.

4. La actuación de Palacios se convertiría en el test principal de la apuesta del PS por un camino electoral, reformista y parlamentario. Sus intervenciones en la cámara -en oposición a la Ley de Residencia y en pos de leyes como el divorcio, la reducción de la jornada laboral y la implantación de un régimen sobre accidentes de trabajorecibirán gran cobertura en las páginas de $L V$, que comenzaría a tener una sección permanente dedicada a reseñar los debates parlamentarios. 
impulsó su derogación y la vuelta al sistema de lista completa (Castro, 2012: 158). La Vanguardia reconocía que "la ley electoral por distrito, resultaba con todos los defectos que se le atribuyen, un positivo adelanto en la materia" y afirmaba que lo que debía hacerse era mejorarla "estableciendo el secreto del voto, y hacer efectivas las penas para los infractores". En lugar de ello, lamentaban, se cambiaba el sistema, volviendo al de lista, sin incorporar tampoco el voto secreto $(L V, 22$ de julio de 1905). Sin embargo la crítica era puntual y no tendría consecuencias, el PS no llevó adelante ninguna acción en defensa de la ley electoral. ${ }^{5}$

Quintana falleció a mediados de 1906. Aunque su sucesor, José Figueroa Alcorta, proclamó insistentemente la necesidad de una reforma electoral, sus propuestas nunca pasaron de proyectos que ni siquiera alcanzaron estado parlamentario. El escepticismo que los socialistas habían mostrado frente a los discursos reformistas de Figueroa Alcorta se mantuvo cuando el candidato que éste impulsó, Roque Sáenz Peña, alcanzó la Presidencia. Los socialistas desconfiaban de Sáenz Peña, tanto por su pasado juarizta como por su filiación católica; pero también rechazaban los puntos centrales del proyecto que, a poco de asumir, el Poder Ejecutivo envió al Parlamento: el sistema de lista incompleta ${ }^{6}$ y el voto obligatorio. ${ }^{7}$ Algunos socialistas pidieron que el PS se movilizara en oposición al sistema de lista incompleta $(L V, 13$ de agosto de 1911) y el CE remitió una nota a la Cámara de Diputados declarando su preferencia por la representación proporcional o, en su defecto, las circunscripciones uninominales ( $L V, 26$ de agosto de 1911). Sin embargo a este tono crítico se contrapuso la voz de Justo quien, tal vez temiendo que las críticas confundieran a los socialistas con los que se oponían a toda reforma, respondió a una encuesta de La Nación evaluando que la lista incompleta podía tener el efecto positivo de "imponer la concordancia entre las facciones afines" ( $L V, 27$ de agosto de 1911). Cuando, a fines de noviembre, la Cámara de Diputados aprobó la lista incompleta, $L V$ publicó un editorial que, abriendo la campaña electoral,

5. Probablemente a ello contribuyera la fuerte disputa que en esos días enfrentaba al núcleo justista, tradicionalmente dominante, con el sector "sindicalista" que bregaba por acentuar el perfil obrero del Partido (Belkin, 2007).

6. Por este sistema cada votante podía sufragar sólo por dos tercios de los cargos en disputa lo que, se suponía, haría que la primera fuerza ocupara esos dos tercios a la vez que permitía que los votantes de una segunda fuerza colocara a algunos de sus candidatos para ocupar el tercio restante. En su práctica, como veremos al referirnos a los comicios de 1912, el sistema permitiria que incluso más de dos listas lograran hacer elegir a alguno de sus candidatos.

7. El voto obligatorio sería también uno de los principales blancos de la crítica de los sindicalistas quienes encontraban en él una prueba de que las elecciones constituían un engranaje de la dominación burguesa (Belkin, 2013). 
señalaba que, más allá de las bondades y defectos de ese sistema, los socialistas debían ser más disciplinados que nunca, ya que las nuevas circunstancias políticas -cambio de sistema electoral, nuevo padrónles permitirian "contarse" ( $L V, 26$ de noviembre de 1911). Aunque el artículo concluía apelando a la decisión de triunfar, la perspectiva de victoria aparecía como lejana y el tono más bien parecía remitir a una revista de las propias fuerzas para futuros combates.

Esta visión pesimista aparecía reforzada por la desconfianza con la que se observaba la otra pieza central del proyecto de reforma: el voto obligatorio. Los socialistas no sólo consideraban que el planteo invertía los términos del problema -si el pueblo no votaba era por falta de cultura y por lo tanto debía desarrollarse ésta antes de empujar a los ciudadanos al comicio- sino que temían lo que consideraban -apoyándose en precedentes belgas, españoles e italianos- como una medida eminentemente conservadora que intentaba diluir el peso de las "minorias avanzadas" con la fuerza "de la opinión chata y rutinaria de las campañas" ( $L V, 16$ de agosto de 1911). Pero la sanción del voto obligatorio, aunque negativa, era considerada inevitable ( $L V, 1$ de diciembre de 1911). Por eso, grande fue la sorpresa de los socialistas cuando ese mismo $1^{\circ}$ de diciembre, el voto obligatorio fue rechazado por la Cámara de Diputados. Desde $L V$ se recordaba que para reconsiderar la medida eran necesarios dos tercios de los votos de la comisión, por lo que concluía: "Puede asegurarse, pues, que el voto obligatorio está muerto. Felicitémonos de ello" ( $L V, 2$ de diciembre de 1911).

Sin embargo poco duró el júbilo socialista. El 9 de febrero $L V$ titulaba "Ya tenemos reforma electoral", e informaba que habian sido aprobados tanto el sistema de lista incompleta como el voto obligatorio. Con respecto al primero se explicaba que se lo había preferido al voto uninominal, que había sido desechado por "revolucionario": la oligarquía había pretextado la eliminación de las luchas de los caudillos barriales, pero en el fondo lo que se buscaba era "disminuir las probabilidades de que el PS haga valer sus votos en los distritos obreros, alcanzando resultados que con el sistema adoptado serán más problemáticos”. En lo que hacía al voto obligatorio, que a diferencia de juicios previos era considerado como "lo principal de la nueva ley", era visto como "un salto al vacío que puede dejarnos malparados" ( $L V, 9$ de febrero de 1912). El juicio socialista combinaba clarividencia con cortedad de miras: pronto el voto obligatorio se mostraría sí como "lo principal de la nueva ley" y también como un salto al vacío, pero para su sorpresa, el PS saldría, al menos en el corto plazo, más beneficiado que lo esperado. 


\section{La Ley Sáenz Peña puesta a prueba}

Pocos días después de aprobada la reforma, $L V$ estimaba que sus efectos serian escasos. Sostenía que a cinco semanas de las elecciones se observaba "un quietismo enervante" ya que, salvo por la agitación de los socialistas, no se observaba "ningún rasgo de acción cívica por parte de las otras agrupaciones" que mantenían sus inveteradas prácticas, "ese manipuleo de nombres, esas contradanzas y cabildeos (...) para cumplimentar a los amigos, para saciar los apetitos de los cómplices, para ubicar al recomendado". El diagnóstico concluía con el viejo deseo de los socialistas, la simplificación del sistema político (Martínez Mazzola, 2005): "Urge para el país y para la mayor eficacia de nuestro desenvolvimiento que los grupos sociales adquieran la conciencia de sus intereses políticos". Hasta el presente, concluía el artículo, sólo lo había hecho la clase obrera a través del PS, en tanto las demás clases sociales, que también eran víctimas de la oligarquía, se resignaban a conceder cobardemente "la carta blanca [...] para que los terratenientes adueñados del gobierno concluyan por extorsión y asfixia con las más elementales manifestaciones de la vida social del pueblo" ( $L V, 23$ de febrero de 1912).

Al comenzar la campaña, el escepticismo dejó paso a un discurso que planteaba las ventajas de la nueva situación, subrayando que la mayoría de los nuevos votantes que incorporaría el voto obligatorio eran trabajadores que antes habian estado alejados de las urnas, a los que se instaba a dar su voto a los socialistas que protegerian sus ingresos de los altos impuestos y defenderian sus organizaciones ( $L V, 9$ de marzo de 1912). Un tono optimista caracterizaba al manifiesto que el Comité Ejecutivo y el Comité Electoral emitieron el 17 de marzo. Ese optimismo, que los hacía proclamar "conquistaremos, dentro de poco, la Capital Federal", no aparecía justificado en términos de las nuevas reglas electorales, sino por una larga historia de luchas que, en dificiles circunstancias, había dado lugar a un progreso lento pero firme, "que no da lugar al retroceso". Con respecto a la reforma, se la calificaba como "de alcances medianos", y, luego de ponderar el sistema proporcional, se destacaba que con la lista incompleta un gran número de ciudadanos, entre los que imaginaban encontrarse ellos, quedaría sin representación $(L V, 18$ de marzo de 1912). Sin embargo, a dos dias de transcurrido el comicio, y ya con los primeros datos del escrutinio, los socialistas comenzaron a entrever el buen resultado obtenido. $L V$ subrayaba que a partir de ese momento "el Partido Socialista tiene conquistada la más alta personería política, negada hasta ahora tácitamente por los bandos oligárquicos". Al finalizar el escrutinio provisional, el PS obtuvo dos bancas, junto a 
ocho radicales, Luis Drago de la Unión Cívica y Estanislao Zeballos de la Unión Nacional.

El éxito electoral, que había permitido la llegada al Parlamento de dos diputados socialistas, modificaba el lugar del PS en el sistema político, así como las tareas que debía llevar adelante. Tal era el argumento del editorial que abría el número especial que $L V$ publicó el $1^{\circ}$ de mayo, que explicaba que en el acto de ese día se festejaba, junto al Día del Trabajo, "la consagración del socialismo como fuerza política positiva", la única en un país que empezaba a aprender los primeros pasos de la democracia. La enumeración de las distintas etapas de desarrollo del partido -sus primeros pasos donde su insignificancia se perdía "en la inmensidad de la Babel cosmopolita", el primer jalón obtenido con el triunfo "con pocos centenares de votos" de Palacios en 1904- brindaba el marco para subrayar el modo en que habia variado su "posición", y convocar a las filas socialistas. Pero esta convocatoria dejaba ver un nuevo desafio: la fuerza interna del partido, su militancia, debía acompasar el súbito crecimiento de su "fuerza externa, la influencia socialista en el pueblo", expresada en las recientes elecciones.

Pronto los efectos de la Ley Sáenz Peña fueron testeados nuevamente: los resultados responderían, al menos por el momento, a las expectativas socialistas. En marzo de 1913 tuvieron lugar nuevas elecciones nacionales, convocadas para llenar dos bancas de diputados y una de senador por la Capital. En las elecciones de diputados Nicolás Repetto y Mario Bravo obtuvieron más de 48.000 votos, aventajando cómodamente al radical Lauro Lagos que con algo más de 30.000 obtuvo la tercera banca. En la elección de senadores, Enrique Del Valle Iberlucea recibió 41.484 votos contra 30.748 de Leopoldo Melo de la UCR. Al conocerse los primeros cómputos, $L V$ explicaba que el "ruidoso triunfo" del PS daba cuenta del "camino progresivo" que el electorado de la Capital había recorrido en tan solo un año bajo la influencia de "la fecunda y brillante acción parlamentaria de los diputados socialistas" ( $L V, 1$ de abril de 1913). El triunfo socialista fue shockeante tanto para las fuerzas politicas tradicionales -Carlos Ibarguren daba cuenta del "pánico" que se había manifestado en una reunión de senadores conservadores a la que había expresado su solidaridad el único senador radical, José Camilo Crotto- como para los "grandes diarios". La Prensa consideraba que el resultado mostraba lo aventurado de las reformas de Sáenz Peña y Gómez, y planteaba la necesidad de volver atrás con las reformas; La Nación criticaba el voto a una fuerza formada por extranjeros, para luego consolarse con el argumento de que el triunfo no se debía al voto socialista sino al del electorado independiente y conservador, tendencialmente cívico. En el caso del radicalismo, la derrota derivó en un recrudecimiento del discurso anti-extranjero -que adoptaba un 
argumento similar al empleado por La Nación- y en la denuncia, por parte de su Comité Nacional,

de una siniestra conjuración tramada por el régimen imperante en el país, que en la imposibilidad de realizar aquí los fraudes y las agresiones puestos en juego en el interior de la república, no ha vacilado en prestar su concurso a una secta, compuesta en su mayor parte de extranjeros sistemáticamente enemigos de todo bien común. (Citado en Garguin, 1999: 168)

Estos argumentos fueron descartados por los socialistas -considerándolos "fantásticos y absurdos", fruto del temor y el criterio trastornado de mucha gente, entre ellos los redactores de los grandes diarios $(L V, 3$ de abril de 1913)- que explicaban que además de los votos tradicionalmente socialistas habian recibido los de "los electores que no pertenecian a ningún partido [...] y que han adquirido bastante experiencia para emplear sus sufragios inteligentemente", y los de la legión de "ciudadanos desencantados con el radicalismo, que ante la esterilidad de sus representantes parlamentarios han decidido retirarles su apoyo" ( $L V$, 9 de abril de 1913). Estas explicaciones fueron compartidas por otros observadores de la época, como los miembros de la Revista Argentina de Ciencia Política, en particular por su director Rodolfo Rivarola, que adjudicó el triunfo a la existencia de un voto independiente que se había orientado, en esta ocasión, principalmente hacia los socialistas.

Como había sucedido en 1913, los comicios de renovación parlamentaria realizados en la ciudad de Buenos Aires en marzo de 1914, produjeron un nuevo triunfo del PS cuyos candidatos obtuvieron más de 40.000 votos y siete bancas. Los radicales ganaron las tres restantes, mientras que civicos y constitucionales no obtuvieron representantes. Después de las elecciones, la animadversión que había caracterizado las relaciones entre socialistas y radicales durante la campaña electoral se acentuó. Por otro lado, el crecimiento del bloque parlamentario, que permitía a los socialistas abrigar fuertes expectativas con respecto al "año parlamentario" que estaba por abrirse, no hacia más que acentuar la importante cuestión de las relaciones con un radicalismo que también se habia fortalecido por sus recientes triunfos en las elecciones del interior del país. En ocasiones los socialistas trazaban un paralelo positivo entre ambas fuerzas en crecimiento; es el caso de un editorial de $L V$ que, planteando un elogio del radicalismo, sostenía que en las últimas elecciones "y al amparo de la nueva ley electoral" se había dado una polarización del "espíritu público" en torno de agrupaciones que representaban, aunque fuera "a medias" como en el caso radical, "una verdad y un principio", quedando atrás "la vieja oligarquía" ( $L V, 18$ de abril de 1914). 


\section{Los dolores del crecimiento}

A sólo dos años de sancionada la Ley Sáenz Peña, el PS se había impuesto en dos elecciones en la Capital Federal. Sus votos se habian quintuplicado con respecto a la última elección previa a la reforma electoral, ${ }^{8}$ y tenía nueve diputados y un senador nacional.

Pero no todas eran rosas. Si bien el partido crecía, su crecimiento organizacional era desparejo y centrado en la Capital -de los 72 centros representados al congreso de Rosario sólo 13 estaban ubicados en el interior del país-. Por otro lado, aunque el número de centros porteños se había duplicado, el número de votantes había crecido a un ritmo mucho mayor. Un editorial de La Vanguardia pasaba revista a los resultados electorales y al aumento de la representación parlamentaria del PS, señalando que si bien el número de centros socialistas también había crecido -"la media docena de agrupaciones con que se constituyó, encerradas en los limites de la capital, se han multiplicado hasta llegar hoy a 110, por todas las regiones del país"-, era necesario confesar que estaba lejos de corresponderse con los 55.240 votos obtenidos por el partido en las últimas elecciones. A continuación señalaba que, aunque el objetivo inmediato no era alcanzar la relación de 5 a 1 entre número de votos y de afiliados que tenían los partidos socialistas más sólidos, era necesario profundizar "la organización del pueblo" y para ello se debía intensificar "la propaganda "por la organización" ( $L V, 15$ de mayo de 1914).

Como había sucedido con sus "hermanos mayores" europeos, el ingreso a la política de masas acentuaba la diferenciación entre votantes y militantes socialistas. Esta diferenciación, a pesar del esfuerzo de la conducción partidaria por mantener satisfechas a las dos bases sociales, no dejaría de ocasionar conflictos, particularmente por las tensiones que generaría la búsqueda de aggiornar al partido para obtener nuevos éxitos electorales, que haría surgir la resistencia de núcleos de militantes que sostenian posturas más "obreras", "revolucionarias" e "internacionalistas", que eran acompañados por buena parte de la militancia gremial y juvenil del PS. ${ }^{9}$

8. Palacios, el candidato más votado del PS en las elecciones de diputados nacionales por la Capital Federal, había obtenido menos de 8.000 votos; en cambio, en las elecciones de marzo de 1914, el menos carismático Repetto recibió casi 45.000 votos.

9. Quienes sostenían estas posiciones, presentes desde los primeros días del PS, y que en 1912 habian establecido un primer núcleo organizativo con la fundación del Centro de Estudios Sociales Carlos Marx y la publicación del periódico Palabra Socialista (Corbière, 1984: 16-17), afianzarian su peso en la estructura partidaria con la creación del Comité de Propaganda Gremial. Pocos días antes de la realización del $\mathrm{XII}^{\circ}$ Congreso del PS en Rosario se reunieron en el Centro Socialista de la Sección 
El número especial que $L V$ publicó el $1^{\circ}$ de mayo posterior a las elecciones de 1914 daba prueba clara de este intento por interpelar a la base electoral más amplia que había dado al PS los recientes triunfos electorales. Se abria con un artículo en el que José Rouco Oliva explicaba que, si a cada conmemoración del $1^{\circ}$ de mayo los socialistas le asignaban un motivo especial, ligado con cuestiones de la hora que acompañaban a su significado propio y permanente, el tema de este año no podía ser más que la celebración del triunfo socialista y el afianzamiento de la libertad electoral que implicaba. Este carácter doble de la fecha era reafirmado por el editorial impreso a continuación que explicaba que ese día era para los socialistas de la Argentina "el día del Trabajo y la Democracia", subrayando, ante las posibles prevenciones, que compartian "con el proletariado mundial, los anhelos comunes, las mismas ansias de reivindicaciones generales, la misma esperanza en un régimen mejor", pero a la vez afirmando "el carácter nacional e histórico de nuestro movimiento". El artículo concluía haciendo fe de un "nacionalismo inteligente y sano", alejado del "raro patriotismo" de quienes honraban a la patria sólo en sus símbolos fríos y en su pasado "oscuro y turbulento" y de los gobiernos que con sus "excesos militaristas" arrancaban del hogar y el trabajo a los jóvenes para llevarlos al sacrificio ( $L V, 1$ de mayo de 1914).

En la misma línea se ubicaba el artículo de Francisco Dagnino, que reproducía un poema del líder socialista Emilo Frugoni dirigido "a la plebe gaucha", planteando explícitamente la necesidad de disputar el monopolio que sobre el tema habían tenido "los patriotas de última hora" y un conjunto de "periodistas y poetastros" -cabe recordar que pocos meses atrás Lugones había dado sus célebres conferencias sobre el Martín Fierro como clave de la identidad nacional-, que habian convertido "el tópico campero" en el "simbólico estandarte siniestro de un patriotismo de pacotilla". Dagnino explicaba que la patria y la nacionalidad sólo serían protegidas "cuando los pobres y los desamparados auténticos -el gaucho entre ellos- sean admitidos de verdad, y no con lírica hipócrita,

$12^{\mathrm{a}}$ los delegados de 22 centros socialistas de Capital Federal y el Gran Buenos Aires, para crear un organismo que tuviera por objeto "constituir sindicatos gremiales entre los obreros de un mismo oficio que aún no estén organizados en sociedad; intensificar la propaganda gremial [...]; uniformar las organizaciones a constituir y las ya existentes mediante una eficaz y positiva reglamentación (citado en Camarero y Schneider 1991: 78-79). A pesar de no cuestionar explícitamente la línea partidaria con respecto a las organizaciones gremiales, la acción del Comité de Propaganda Gremial sería percibida como una amenaza por la dirección partidaria, que no sólo no le daría apoyo sino que aún, como señalan Camarero y Schneider (1991), abriría las páginas de $L V$ para que el dirigente sindicalista Marotta cuestionara las posiciones adoptadas por el agrupamiento gremial socialista. 
a formar parte de esa sociabilidad argentina". El planteo concluía con una afirmación fuertemente iluminista: "A los gauchos, a los proletarios del campo, debemos enseñarles que, a fuer de héroes se puede y es más útil ser ciudadanos conscientes" ( $L V, 1$ de mayo de 1914).

Pero el esfuerzo por destacar el carácter "nacional" del socialismo no obedecía solamente a una discusión general con los ideólogos nacionalistas, sino a los rumores acerca de la formación de un "socialismo nacional". Esto lo hacía explícito un artículo, también de Francisco Dagnino que, abandonando su tradicional preocupación por cuestiones literarias, subrayaba que la constitución de tal fuerza no tenía sentido debido a que el PS ya era "el único partido auténtica y genuinamente nacional" por ser quien, despreciando "la charla patriotera por inconcluyente", impulsaba el movimiento político moderno y suscitaba esperanzas "en todas las clases populares". Como vemos, el énfasis en el carácter nacional del partido se ligaba con una redefinición de aquéllos a quienes se dirigía: luego de la aprobación de la Ley Sáenz Peña, los socialistas tendian a interpelar menos al proletariado y más a un "pueblo" de carácter más indefinido ( $L V, 14$ de mayo de 1914).

\section{El XII Congreso del PS}

Como dijimos, estas transformaciones -no sólo las identitarias ligadas a la adopción de un discurso menos obrero y más "nacionalista", sino también las organizativas relacionadas con las necesidades de una estructura en rápido crecimiento- no dejaban de suscitar resistencias en las filas partidarias, las que, se temía, podian estallar en el XII Congreso que tendria lugar en Rosario a fines de mayo. El primer gesto de la dirección partidaria para evitar estos conflictos fue la apelación al viejo tópico que enfatizaba la necesidad de centrarse en cuestiones concretas y no en debates doctrinarios y, con ese fin, instar a los centros a elegir "sus delegados de entre sus hombres más experimentados, más capaces y de mayor confianza" ( $L V, 5$ de mayo de 1914). Días después la cuestión parecía hacerse más profunda al discutirse ya no la elección de los delegados sino el mandato que los mismos llevarian al congreso, señalando que, si la noción de un mandato imperativo siempre había sido absurda, en ese momento era del todo "inadmisible". Y pasaba a explicarse que la "libertad de juicio" era particularmente necesaria en momentos en que el crecimiento del partido planteaba condiciones nuevas y más complejas a la acción socialista, lo que imponía la necesidad de centralizar su dirección. Podemos ver que la libertad de los representantes no se planteaba en nombre de la libertad individual sino de la centralización partidaria, la que, sostenía la dirección de $L V$, se vería bloqueada si los delegados en el congreso no pudieran acordar distanciándose de lo decidido en los centros ( $L V, 8$ de mayo de 1914). 
Otra cuestión relacionada con el fortalecimiento electoral, que también ponía de manifiesto las tensiones que el crecimiento generaba en una fuerza que hasta poco tiempo antes no accedía a cargos públicos, era la de la incompatibilidad entre cargos partidarios y cargos electivos. $L V$ señalaba que, aunque eran comprensibles las desconfianzas hacia una excesiva centralización, las mismas no debian llevar a temer que en el PS se entronizara "una especie de oligarquía que, en un partido de libre discusión y de contralor riguroso como el nuestro, no tendría medios de mantenerse, ni objeto que llenar". Indicaba que las "falsas incompatibilidades" que se deseaba imponer no tenian objeto y que, en cambio, implicaban "un agravio para muchos hombres insospechables en su independencia de carácter". El diario socialista planteaba que aunque podia tener sentido estar alerta ante "los elementos que hoy o mañana por sus tocamientos con el gobierno, pueden comprometer la independencia del partido", el PS nada podía ganar "disminuyendo a los hombres que lo sirven por entero y que por su misma situación social clara y definida pueden merecer mayor confianza". El Editorial sostenía que la discusión nacía de una falsa concepción que parecía considerar que el $\mathrm{CE}$ debía "fiscalizar inquisitorialmente [...] a la redacción del diario" y que el salario pagado por el PS tenía un poder de corrupción mayor que el recibido de un patrón o del Estado $(L V, 21$ de mayo de 1914). Este último comentario marcaba el punto en el que la cuestión de las incompatibilidades se tocaba con otro tema que también afectaba las tradiciones partidarias: el de la existencia de funcionarios rentados. Frente a ello, se apelaba a los ejemplos del socialismo francés y alemán para sostener que "nadie podría tomar a mal que el partido (pagara) a quienes absorbe su tiempo, impidiéndole entregarse a otras tareas" ( $L V$, 21 de mayo de 1914).

Más allá de las prevenciones, los conflictos internos ocuparon la mayor parte de las consideraciones del congreso. Ya al comienzo, se vivió un clima de tensión cuando, retomando la cuestión de la incompatibilidad entre cargos partidarios y cargos electivos, la candidatura de Justo a la presidencia del congreso fue resistida por un sector que sostenía que el cargo no debía recaer en un legislador sino en un simple delegado. Justo finalmente se impuso, aunque más de un tercio de los delegados votó por el delegado de 25 de Mayo Román Rodríguez de Vicente, y al ocupar la presidencia dio un discurso reconociendo que el crecimiento electoral experimentado por el partido implicaba mayores responsabilidades y también nuevos riesgos: "Puede asaltarnos el peligro de las ambiciones personales, puede la preocupación del éxito inmediato tender a desviar nuestro juicio" ( $L V, 26$ de mayo de 1914). ${ }^{10}$

10. Una prueba de esos temores la encontramos en la decisión del CE de crear un 
La discusión del informe en el que el $\mathrm{CE}$ daba cuenta de lo actuado por el PS en los años recientes dejó ver que buena parte de las tensiones remitían a las prácticas electorales de un partido en crecimiento, que participaba de comicios más allá del ámbito porteño. Así, la participación de los socialistas de Santiago del Estero en una lista que, bajo el nombre de "Comité del Pueblo", los unía con fracciones de la oligarquía local mereció una condena que no sólo se dirigía al Centro Socialista santiagueño sino también al $\mathrm{CE}$, al que se instaba a que en el futuro vigilara más de cerca la conducta política de las agrupaciones adheridas. También suscitó discusiones el pedido de Ramón Morey, dirigente del socialismo mendocino que recientemente había sido electo como legislador provincial, de una subvención para poder desempeñar un cargo que, a diferencia de los legisladores, no recibia dieta. La propuesta recibió resistencias por parte de quienes, como el militante del Comité de Propaganda Gremial Pedro Zibecchi, consideraban que no se trataría de una subvención sino de una simple retribución por su labor militante. Finalmente la cuestión sería saldada por un mecanismo indirecto: el nombramiento de Morey como corresponsal a sueldo de $L V$ (LV, 26 de mayo de 1914).

Pero la disputa excedía los casos locales, ello se hizo manifiesto al discutirse la creación de una Secretaría Electoral impulsada por el CE. Mientras algunos centros negaban la necesidad de crear ese cargo y otros argumentaban que el monto que la conducción había destinado para quién lo ocupara era excesivo, Zibecchi iba más allá discutiendo las atribuciones que tomaba para sí el $\mathrm{CE}$ al crear un cargo -e incluso nombrar como su ocupante a Marcelino Folgar- sin aval del Congreso partidario. Ante las críticas hizo uso de la palabra el Secretario General del PS Antonio de Tomaso quien buscó dar cuenta de la necesidad del cargo afirmando:

La función crea el órgano. La actividad electoral del Partido ha crecido enormemente, por eso el C.E., que según los estatutos debe ejercer la función de vigilancia de las elecciones, ha decidido crear este órgano que será de gran importancia para el estudio de las situaciones políticas. (LV, 26 de mayo de 1914)

Las palabras de De Tomaso no lograron calmar las dudas de quienes

\footnotetext{
"formulario" que debían firmar todos aquellos que solicitaran el ingreso el PS. El nuevo afiliado, además de aportar datos personales, familiares y de "estado político", debía declarar "conocer y aceptar la declaración de principios, el programa mínimo y el estatuto del Partido". El formulario era enviado al Comité Ejecutivo y solo cuando éste hallaba que no había ningún inconveniente se incorporaba al nuevo afiliado ( $L V$, 24 de mayo de 1914).
} 
objetaban la medida: el congreso rechazó la moción que disponía la creación del cargo de Secretario Electoral y le fijaba una renta. Como podemos ver, no todos en el PS aceptaban la centralidad que la dirección partidaria daba a la cuestión electoral. Prueba de ello sería la protesta, que militantes gremiales como Zibecchi y Martín Casaretto hicieron oír en el congreso, respecto de la brevedad del apartado del informe del CE atinente al movimiento obrero ( $L V, 26$ de mayo de 1914).

Pero si uno de los focos de tensión enfrentaba a la conducción del PS con la izquierda partidaria, que cuestionaba el abandono de lo gremial y la obsesión con los comicios, otro se hallaba en la figura de quien siempre había sido la principal baza electoral del PS, Alfredo Palacios. El legislador sufrió la condena por haber votado a favor de un proyecto de intervención a la Provincia de Salta, adoptando una postura contraria a la definida por el bloque socialista. En su descargo, Palacios dijo que se trataba de la única ocasión en que había actuado sin consultar a sus compañeros de bloque. Justo le respondió citando otras "indisciplinas" y trazando una evaluación general de su actuación general: dijo que Palacios, de cuyo talento no dudaba, siempre se había encontrado "en una situación especial dentro del partido; siendo diputado, nunca asistió a las reuniones del $\mathrm{CE}$; asistió poco o como quiso a las reuniones del grupo parlamentario, y contra la mayoría de éste mantuvo inconmovible su opinión sobre las elecciones de Buenos Aires". Y terminó declarando "si el congreso quiere juzgar...que juzgue y condene a quien no está dentro de la disciplina" (26 de mayo de 1914). Aunque Palacios negó que hubiera habido indisciplina de su parte, su actuación recibió fuertes críticas. Probablemente las más duras, por prever la posible separación del legislador socialista, fueron las de Enrique Dickmann quien señaló que, lo mismo que el legislador cuestionado, él era un hombre de honor pero que, como hombre libre, acataba las resoluciones de la mayoria: "Si no puedo acatar una resolución me retiro del partido. Mientras esté en él, acataré sus resoluciones". Puesta a votación la moción de censura, obtuvo una rotunda mayoria, 2.878 votos contra 151. De mayores consecuencias fue la aprobación por el congreso de un artículo del Estatuto partidario que fijaba mayores obligaciones a los miembros del grupo parlamentario ( $L V, 26$ de mayo de 1914).

Otro punto de tensión entre Palacios y la dirección del PS surgió de la moción, planteada por el legislador socialista, proponiendo que se permitiera que el PS concurriera a sus actos y demostraciones llevando no sólo la bandera roja sino también la argentina. Mientras sectores de la izquierda del PS, como Pedro Zibecchi, rechazaron la propuesta, la conducción partidaria consideró inoportuno abordar un debate que tocaba un punto frágil para la unidad partidaria, "la cuestión nacional". Finalmente, ante voces que consideraban que el tema debía remitirse a 
los centros y a un voto general, se decidió "aplazar" la moción $(L V, 26$ de mayo de 1914).

Pero el punto de mayor conflicto se asociaba con la cuestión del duelo, de vieja data y que antes del congreso había sido reactivada por el frustrado lance entre Palacios y Manuel Ugarte en 1913. Aunque el duelo no llegó a realizarse, Ugarte, quien en esos días enfrentaba públicamente al PS por su posición respecto de la "cuestión nacional", fue separado del PS; el caso de Palacios, en cambio, había sido remitido al congreso partidario por su carácter de representante parlamentario. En el congreso la actitud de Palacios recibió duras críticas, aunque, en consideración a su trayectoria y a su papel de diputado la cláusula que prohibía los duelos fue eliminada. Se hizo pública sin embargo una fuerte censura a su actitud, lo que derivó en que, ante un nuevo duelo de Palacios a solo semanas del congreso, el CE llamara a un voto general que restauró la cláusula. Finalmente un nuevo duelo pautado a mediados de 1915 llevaría a la expulsión del legislador. ${ }^{11}$

Días después, Palacios habló en la Cámara de Diputados, declarando su profunda fe socialista y su orgullo por haber sido el primer representante del PS en el Parlamento, y renunció a su banca. La renuncia fue rechazada por la mayoría de los representantes y también por los diputados socialistas, quienes juzgaban, como afirmaba Enrique Dickmann, que más allá de la disidencia sobre el honor, Palacios era "un Diputado útil para el pueblo que lo ha elegido y [...] un aliado natural, tal vez nuestro único aliado en el recinto de la Honorable Cámara". Sin embargo, Palacios insistió con su solicitud, la que finalmente fue aceptada; el primer diputado socialista abandonaba la Cámara, y aunque trataria de regresar, los votos que obtendría como candidato del recién fundado Partido Socialista Argentino (PSA) serian insuficientes.

\section{Reflexiones finales}

A comienzos de 1915, y en un editorial de $L V$, Enrique Dickmann reconocía que la "rápida y casi inesperada expansión" que el PS había experimentado a partir de la sanción de la Ley Saénz Peña había hecho surgir una nueva serie de problemas en el seno del partido. La fuente de algunos de ellos se hallaba en el exterior, en la "prensa rica" que había reemplazado su politica de silencio respecto al PS por crónicas y editoriales tendenciosos que intrigaban y plantaban cizaña con el fin de suscitar disputas en las filas socialistas. Pero Dickmann reconocía que a esas acciones se sumaba un cambio en el propio PS: ya no se trataba de un "grupito" insignificante, más preocupado por cuestiones teóricas

11. Sólo retornaría al Parlamento en los años 30, luego de su regreso a las filas del PS. 
que prácticas en el que todos formaban "una especie de familia socialista con sus virtudes y defectos en intima comunión ética y mental" y en la que no había "puestos de figuración y provecho" porque todo era abnegación y sacrificio. Las palabras de Dickmann dejaban ver una fuerte desconfianza respecto a las ambiciones que el crecimiento electoral podía despertar. Ante ello, el dirigente socialista apela a un expediente tranquilizador comparando la situación del PS con la de "algunos organismos jóvenes que de repente crecen y se estiran con exceso, produciendo fiebres, dolores, malestares vagos e indefinidos [...] fenómenos pasajeros consecuencia de un ritmo acelerado en el crecimiento, y que paran con la consolidación y robustez del organismo" ( $L V, 7$ de febrero de 1915). La analogía médica, al ligar los problemas a los efectos temporarios de un proceso evolutivo, parecia ofrecer una mirada tranquilizadora. Y, sin embargo, las palabras de Dickmann translucian cierta urgencia por el "peligro" que, si no primaba la serenidad, los triunfos podían traer consigo. Ante ello la salida, usual entre los socialistas era la apelación a la "conciencia", al saber que permitiría al socialismo "conocer los obstáculos que puede encontrar y los peligros que lo amenazan, para prevenirlos y evitarlos a tiempo" (7 de febrero de 1915).

Más allá de las previsiones de Dickmann, el PS no sortearía fácilmente los peligros y desafios nacidos del fuerte crecimiento que había experimentado a partir de la sanción de la Ley Sáenz Peña. Los éxitos electorales llevaron al refuerzo de la dimensión electoral de la práctica socialista, lo que ya había sucedido en 1904 con la elección de Palacios, y al aportar una nutrida representación parlamentaria, contribuyeron a consolidar al grupo parlamentario socialista como un importante foco de poder dentro del partido. Ese peso se pondría en evidencia con particular nitidez en 1917 cuando, al poner en juego sus bancas, los miembros del grupo parlamentario lograron torcer la decisión contraria a la ruptura de relaciones con Alemania, adoptada meses antes en un III Congreso Extraordinario. Los sectores de izquierda que sostenían las posiciones adoptadas en el congreso serían expulsados y poco tiempo después fundarian el Partido Socialista Internacional (Campione, 2005). Por otra parte, y como vimos, la existencia de un bloque numeroso cambiaba la dinámica al interior del grupo parlamentario socialista reforzando el peso de lo colectivo sobre figuras individuales como Palacios, las que deberian disciplinarse o ser expulsadas.

Pero en la expulsión de Palacios jugó también otro factor: el aumento de escala de la movilización política, como consecuencia del crecimiento de la participación electoral que trajo consigo el voto obligatorio implantado por la Ley Sáenz Peña, lo que favoreció el reemplazo de los "partidos de notables" por los "partidos de masas". En el caso del PS, además de conducir al desarrollo de una módica burocracia y, 
con ella, al afianzamiento del poder de la dirección partidaria vis-à-vis los distintos sectores disidentes, ese carácter masivo de las elecciones, unido al mantenimiento de un sistema de "lista", aunque incompleta, hizo que aquellos que cuestionaban a la dirección del partido que, en nombre de la disciplina y la unidad partidaria relegaba toda posición disidente, tuvieran menos recursos para enfrentarla. Y ello porque, como señala Panebianco (1990), la mayor parte de los simpatizantes se identifican con el partido y no con un sector, manteniendo fidelidad ante el mismo y ante los líderes que representan el signo visible de la identidad partidaria. Esto se haría claro cuando, ya expulsado del PS, Alfredo Palacios, el más popular de los dirigentes socialistas, fracasara en su intento de retornar a la Cámara por un recién fundado Partido Socialista Argentino. Finalmente ni "socialistas argentinos" ni, a pesar de contar con un caudal mucho más amplio de militantes socialistas, "socialistas internacionales" lograrian arrastrar una parte considerable del voto socialista. ${ }^{12}$

Finalmente, la Ley Sáenz Peña tuvo consecuencias importantes en la organización del PS por una tercera vía, más indirecta. Al colocar al PS en una posición más relevante dentro del sistema político, y al darle una representación parlamentaria relevante, obligó a los socialistas a tomar un papel activo en cuestiones que podian dividir a las propias filas, e incluso a los miembros del grupo parlamentario. ${ }^{13}$ Una de las cuestiones clave de la política de la época, la de las intervenciones provinciales, tensaría la relación entre Palacios y el resto de sus compañeros de bloque para ser luego el detonante de la ruptura de los socialistas independientes (Martínez Mazzola, 2011); otra, la de la actitud ante la Gran Guerra, dispararia la ruptura de los "internacionalistas".

\section{Bibliografia}

Belkin, Alejandro (2007), Sobre los origenes del sindicalismo revolucionario en Argentina, Buenos Aires: Ediciones del CCC.

12. En todo caso, y dado el importante núcleo de dirigentes gremiales y juveniles que participaron de la ruptura "internacionalista", una de sus principales consecuencias sería acentuar aún más la importancia de lo electoral en la vida del PS.

13. El vínculo entre partido socialista y grupo parlamentario constituye un problema en muchos partidos socialistas. Como señala Noëlline Castagnez (2006) respecto al socialismo francés, la tensión entre una fuerza que hace un culto de la disciplina partidaria y su bloque parlamentario suele acentuarse cuando el crecimiento del número del grupo de parlamentarios socialistas los coloca en una posición más importante dentro del sistema político, empujándolos a posicionarse en cuestiones que van más allá de la defensa de la clase obrera. 
- (2013), "La crítica del sindicalismo revolucionario al parlamentarismo", Archivos de historia del movimiento obrero y la izquierda, $\mathrm{n}^{\circ} 3$, septiembre.

Camarero, Hernán y Alejandro Schneider (1991), La polémica Penelón-Marotta (marxismo y sindicalismo soreliano, 1912-1918), Buenos Aires: CEAL.

Campione, Daniel (2005), El comunismo en Argentina. Sus primeros pasos, Buenos Aires; Ediciones del CCC.

Castagnez, Noëlline (2006), "Discipline partisanne et indisciplines parlementaires", Parlement (s), Revue d'histoire politique, 2006, n6, pp.4 y 40-56.

Castro, Martín (2012), El ocaso de la república oligárquica. Poder, politica y reforma electoral (1898-1912), Buenos Aires: Edhasa.

Corbière, Emilio (1984), Orígenes del comunismo argentino, Buenos Aires: CEAL.

Garguin, Enrique (1999), "La marea roja. El triunfo socialista en las elecciones porteñas de 1912", en Sociohistórica. Cuadernos del CISH, N 6, La Plata, pp. 147-181.

Martinez Mazzola, Ricardo (2005), "Entre radicales, roquistas y pellegrinistas. El Partido Socialista durante la segunda presidencia de Roca (1898-1904)", en Hernán Camarero y Carlos Herrera (comps.) El Partido Socialista en Argentina. Sociedad, politica e ideas a través de un siglo, Buenos Aires: Prometeo, pp.75-96.

- (2011), "Entre la autonomía y la voluntad de poder. El proyecto de intervención a la Provincia de Buenos Aires y la ruptura del PS en 1927", en Sociohistórica. Cuadernos del CISH, n 28, La Plata, pp.77-107.

Oddone, Jacinto (1983), Historia del socialismo argentino, Buenos Aires: CEAL.

Panebianco, Angelo (1990), Modelos de partido. Organización y poder en los partidos politicos, Madrid, Alianza.

Poy, Lucas (2014), Los origenes de la clase obrera argentina. Huelgas, sociedades de resistencia y militancia politica en Buenos Aires, 1888-1896, Buenos Aires: Imago Mundi.

Scherlis, Gerardo (2005), "El PS y la reforma electoral de 1912", en Mario Justo López (comp.) De la república oligárquica a la república democrática. Estudio sobre la reforma politica de Roque Sáenz Peña, Buenos Aires: Lumiere, pp. 418-483.

Torre, Juan Carlos (2012), "El primer triunfo socialista", en Juan Carlos Torre, Ensayos sobre movimimento obrero y peronismo, Buenos Aires: Siglo XXI.

$$
* * *
$$

Titulo: Temporary Ills? The Partido Socialista in face of Sáenz Peña Law's consequences

Resumen: En este artículo nos proponemos dar cuenta del impacto de la Ley Sáenz Peña, que ampliaba el universo de participación política, sobre la orga- 
nización y la vida interna del Partido Socialista (PS). Comenzaremos pasando revista a las posiciones del PS en los debates que condujeron a la sanción de la Ley Sáenz Peña. A continuación abordamos el modo en que fueron recibidos los, sorprendentemente positivos, resultados socialistas en las elecciones porteñas que siguieron a la sanción de la reforma electoral. En tercer lugar, y centrándonos en el XII Congreso del PS, realizado en 1914, analizamos el modo en que los propios socialistas percibieron los desafios nacidos del crecimiento experimentado por el partido a partir de la sanción de la nueva legislación electoral. Concluimos planteando algunos argumentos más generales respecto a los desafios a los que los socialistas se vieron sometidos a partir de la vigencia de la Ley Sáenz Peña.

Palabras clave: Partido Socialista - Reforma electoral - Cuestión nacional Partidos Políticos

Abstract: In this article we propose to account for the impact of Sáenz Peña Law,
which extended the universe of political participation, on the organization and
internal life of the Partido Socialista (PS). We begin by reviewing the positions
of the PS in the discussions that led to the enactment of the Saenz Peña Law.
Here we address the way in which the surprisingly positive socialist results were
received in the Buenos Aires elections that followed the passage of the electoral
reform. Third, and focusing on the PS's XIIth Congress, held in 1914, we analyze
how the socialists themselves perceived the challenges born from the growth
experienced by the party after the enactment of the new electoral law. We con-
clude by considering some more general arguments regarding the challenges
that the Socialists were under, from the effective date of the Sáenz Peña Law.
Keywords: Partido Socialista - Electoral reform - National Question - Political
Parties

Recepción: 31 de enero de 2015. Aprobación: 28 de febrero de 2015. 